\title{
Associations of Serum Isoflavone, Adiponectin and Insulin Levels with Risk for Epithelial Ovarian Cancer: Results of a Case-control Study
}

\author{
Seiko Otokozawa ${ }^{1}$, Ryoichi Tanaka², Hiroshi Akasaka ${ }^{3}$, Eiki Ito ${ }^{2}$, Sumiyo \\ Asakura1 $^{1}$, Hirofumi Ohnishi' ${ }^{1}$,Shigeyuki Saito ${ }^{4}$, Tetsuji Miura ${ }^{3}$, Tsuyoshi Saito², \\ Mitsuru Mori'1*
}

\begin{abstract}
Background: The aim of this study was to examine the association of serum isoflavones, adiponectin, and insulin levels with ovarian cancer risk. Materials and Methods: We gathered cases with histologically confirmed epithelial ovarian cancer at Sapporo Medical University Hospital from October 2010 to September 2012. Potential controls were recruited from female inpatients without any history of cancer or diabetes mellitus in different wards of the same hospital over the same period of time. Serum isoflavones, adiponectin, and insulin levels were measured in order to estimate associations with ovarian cancer risk in a case-control study. Data from 71 cases and 80 controls were analyzed with a logistic regression model adjusting for known risk factors. Results: A significant reduction in ovarian cancer risk was observed for the high tertile of serum daidzein level versus the low $\left(P_{\text {trend }}<0.001\right)$. A significant reduction in ovarian cancer risk was also observed for the high tertile of serum glycitein level versus the low $\left(P_{\text {trend }}=\mathbf{0 . 0 0 5}\right)$. Furthermore, a significant reduction in ovarian cancer risk was observed for the high tertile of serum adiponectin level versus the low $\left(P_{\text {trend }}=0.004\right)$. Conversely, serum insulin level showed significantly elevated risk for ovarian cancer with the high tertile versus the low $\left.P_{\text {trend }}<0.001\right)$. Conclusions: Decreased serum isoflavones levels, such as those for daidzein and glycitein, decreased serum adiponectin levels, and increased serum insulin levels could be shown to be associated with elevated risk of ovarian cancer.
\end{abstract}

Keywords: Case-control study - isoflavones - insulin - adiponectin

Asian Pac J Cancer Prev, 16 (12), 4987-4991

\section{Introduction}

Ovarian cancer is the most frequent cause of death among gynecologic cancers (Parkin et al., 2005). The incidence rates of ovarian cancer vary considerably across countries and regions. Dietary risk factors for ovarian cancer have been suggested to be related to the regional variation in the incidence rates.

Isoflavones in soy products, such as genistein, can induce both apoptotic and autophagic ovarian cancer cell death, and inhibit angiogenesis (Gossner et al., 2007). Previous studies indicated that the appearance of isoflavones is inversely related to the risk of hormonerelated cancers, including breast, prostate, and endometrial cancers (Yamamoto et al., 2007; Lee et al., 2003; HornRoss et al., 2003). A recent meta-analysis showed that isoflavones, as well as soy foods were significantly associated with a reduced ovarian cancer risk $(\mathrm{Qu}$ et al., 2014). Isoflavones are estrogen-like chemical compounds present in plants that bind estrogen receptors and have both weak estrogenic and weak anti-estrogenic effects. Equol is a kind of isoflavonoids metabolized from daidzein (Rüfer et al., 2006) by bacteria flora in the intestines (Wang et al., 2005). While endogenous estrogenic hormones such as estradiol are steroids, but equol is a nonsteroidal estrogen and has greater estrogenic activity than daidzein.

Adiponectin, the most abundant adipokine, has been suggested to have anti-angiogenic, anti-inflammatory and anti-apoptotic properties (Fantuzzi, 2005; Lihn et al., 2005; Roberts et al., 2010). Serum adiponectin level has been shown to be associated with a reduced risk of not only endometrial cancer (Luhn et al., 2013), but also breast and colon cancers (Gulcelik et al., 2012). Furthermore, a clinical study showed that significantly reduced adiponectin receptor expression was found in colorectal cancer patients (Ayyildiz et al., 2014).

Several studies have found that high insulin levels carry increased risk of cancers including colon, rectum,

${ }^{1}$ Department of Public Health, ${ }^{2}$ Department of Obstetrics and Gynecology, ${ }^{3}$ Department of Cardiovascular, Renal and Metabolic Medicine, ${ }^{4}$ Department of Nursing, Sapporo Medical University School of Health Sciences, Sapporo, Japan *For correspondence: mitsurum@sapmed.ac.jp 
and endometrium (Giovannucci, 1995; Troisi et al, 1997; Schoen et al., 1999). Insulin and insulin-like growth factor-I (IGF-I) have been implicated in the development of colorectal cancer (Kaaks et al., 2000). A nested casecontrol study has successfully related elevated circulating IGF-I levels with ovarian cancer risk at ages younger than 55 years old (Lukanova et al., 2002), and IGF-I was shown to be involved in the development and progression of ovarian cancer through experimental research in the literature (Brokaw et al., 2007).

Established risk factors for ovarian cancer are obesity, lesser use of oral contraceptive pills, use of fertility drugs, decreased amount of parity, and a family history of ovarian cancer (Piver et al., 1996; Collaborative Group on Epidemiological Studies of Ovarian Cancer, 2008; Rizzuto et al., 2013; Valladares et al., 2014). Accordingly, the aim of this study is to examine the association of serum isoflavones, adiponectin and insulin levels with the risk of ovarian cancer while adjusting for these known risk factors.

\section{Materials and Methods}

We collected cases with histologically confirmed epithelial ovarian cancer at Sapporo Medical University Hospital from October 2010 to September 2012. Potential controls were gathered from female inpatients in different wards of the same hospital over the same period. Patients with cancer at other sites or diabetes mellitus were excluded from the control group. Most of the control subjects were primarily diagnosed with having hypertension, cardiac insufficiency, atrial or ventricular tachycardia, or other circulatory diseases.

Information on demographic, anthropometric, and reproductive variables was obtained using a self-administrated structured questionnaire. Clinical information, including histologic types of ovarian cancer, such as serous, endometrioid, clear cell, and mucinous carcinomas, was collected following hospital protocol. Comparison of these serum levels was also performed according to histologic types of ovarian cancer.

All blood samples were obtained after fasting early in the morning. All serum isoflavones such as genistein, daidzein, glycitein, and equol, were measured using a liquid chromatography mass spectrograph; LC-MS/MS, Insulin and high molecular weight (HMW) adiponectin levels were measured using Chemiluminescent Enzyme Immunoassays (CLEIA) with sensitivities of $0.31 \mu \mathrm{IU} /$ $\mathrm{mL}$ and $0.20 \mu \mathrm{g} / \mathrm{mL}$, respectively. All analyses were performed at a special reference laboratory (SRL Co., Tokyo Japan).

Descriptive statistics including mean (SD; standard deviation) and median values (interquartile ranges) for continuous or ordinal variables as well as proportions for categorical variables were computed for both the case and control groups. Comparisons were made between the case and control groups using a chi-square test for categorical variables, and with the Mann-Whitney test for continuous or ordinal variables. A Bonferroni correction was used for the multiple comparison.

Odds ratios (OR) and $95 \%$ confidence intervals (95\%
CI) for ovarian cancer risk were estimated according to the tertile of genistein, daidzein, glycitein, adiponectin and insulin levels through analysis of the unconditional logistic regression model, adjusting for potentially confounding variables such as age, body mass index (BMI), oral contraceptive usage, fertility drugs usage and amount of parity. Significance level was set at $5 \%$. We conducted all analyses using SPSS version 18 (SPSS Inc., Chicago, IL, U.S.A.). The study was approved by the Institutional Review Board at Sapporo Medical University, and written informed consent was obtained from every participant.

\section{Results}

As shown in Table 1, the proportion of the cases with histories of ovarian cancer in a mother or sister was significantly higher than that of the controls $(p=0.047)$. However, age, BMI, frequency of oral contraceptive usage and fertility drug usage, and the amount of parity were not different between the cases and the controls. Serum levels of daidzein $(\mathrm{p}<0.001)$ and glycitein $(\mathrm{p}=0.010)$ were significantly lower in the cases than in the controls. Although it was not significant, serum adiponectin level was lower in the cases than in the controls $(\mathrm{p}=0.090)$. Serum insulin levels were significantly higher in the cases than in the controls $(\mathrm{p}<0.001)$.

Table 2 showed ORs and 95\% CIs of epithelial ovarian

Table 1. Baseline Characteristics and Serum Levels of Isoflavones, Adiponectin, Insulin in the Epithelial Ovarian Cancer Cases and the Controls

\begin{tabular}{|c|c|c|c|}
\hline Items & Case $(\mathrm{N}=71)$ & Control $(\mathrm{N}=80)$ & $\mathrm{p}$ value \\
\hline \multicolumn{4}{|c|}{ Mean age $(\mathrm{SD})$ in years } \\
\hline & $57.4(11.7)$ & $56.3(14.5)$ & 0.807 \\
\hline \multicolumn{4}{|c|}{ Mean body mass index $(\mathrm{SD})$ in $\mathrm{kg} / \mathrm{m}^{2}$} \\
\hline & $21.8(3.3)$ & $21.4(4.0)$ & 0.198 \\
\hline \multicolumn{3}{|c|}{ Oral contraceptive use, no (\%) } & 0.123 \\
\hline Never & $66(93.0)$ & $68(85.0)$ & \\
\hline Has used & $5(7.0)$ & $12(15.0)$ & \\
\hline \multicolumn{3}{|c|}{ Fertility drugs, no (\%) } & 0.862 \\
\hline Never & $67(94.4)$ & $76(85.0)$ & \\
\hline Has used & $4(5.6)$ & $4(5.0)$ & \\
\hline \multicolumn{3}{|l|}{ Parity $(\%)$} & 0.506 \\
\hline 0 & $21(29.6)$ & $20(25.0)$ & \\
\hline $1-2$ & $36(50.5)$ & $48(60.0)$ & \\
\hline$>2$ & $14(19.7)$ & $12(15.0)$ & \\
\hline \multicolumn{4}{|c|}{ History of ovarian cancer in a mother or sister $(\%)$} \\
\hline No & $67(94.4)$ & $80(100.0)$ & $0.047 \#$ \\
\hline Yes & $4(5.6)$ & $0(0.0)$ & \\
\hline \multicolumn{4}{|l|}{ Isoflavones } \\
\hline \multicolumn{4}{|c|}{ Genistein (ng $/ \mathrm{mL})$, median [interquartile range] } \\
\hline & $4[18.9,82.7]$ & $49.9[20.2,143.1]$ & 0.259 \\
\hline \multicolumn{4}{|c|}{ Daidzein (ng /mL), median [interquartile range] } \\
\hline & $9.0[4.6,19.8]$ & $22.2[7.1,67.7]$ & $<0.001$ \\
\hline \multicolumn{4}{|c|}{ Glycitein (ng /mL), mean (SD) } \\
\hline & $0.8(1.4)$ & $2.8(4.7)$ & 0.010 \\
\hline \multicolumn{4}{|c|}{ Equol (ng /mL), mean (SD) } \\
\hline & $1.9(5.6)$ & $4.0(10.0)$ & 0.190 \\
\hline \multicolumn{4}{|c|}{ Adiponectin $(\mu \mathrm{g} / \mathrm{mL})$, mean $(\mathrm{SD})$} \\
\hline & $6.0(3.0)$ & $7.9(5.6)$ & 0.090 \\
\hline \multicolumn{4}{|c|}{ Insulin $(\mu \mathrm{IU} / \mathrm{mL})$, mean $(\mathrm{SD})$} \\
\hline & $11.9(9.2)$ & $7.1(6.0)$ & $<0.001$ \\
\hline
\end{tabular}

SD: standard deviation; \#: the Fischer's exact probability method 
Serum Isoflavone, Adiponectin and Insulin Levels and Risk for Epithelial Ovarian Cancer: Results of a Case-Control Study

cancer risk according to serum levels of isoflavones, adiponectin, and insulin. Model 1 included variables such as age, BMI, oral contraceptive usage, fertility drug usage, and parity for adjustment. Because of being absent in the controls, a history of ovarian cancer in a mother or sister could not be included in any model. Model 2, Model 3, and Model 4 included additional variables daidzein, insulin, and daidzein and insulin, respectively. A significant reduction in ovarian cancer risk was observed for the high tertile of serum daidzein level versus the low (OR, 0.13; 95\% CI, 0.05-0.38) in Model 3 (Ptrend<0.001), as well as in Model 1. A significant reduction in ovarian cancer risk was also observed for the high tertile of serum glycitein level versus the low (OR, 0.20; 95\%CI, 0.080.55) in Model 3 (Ptrend=0.005), as well as in Model 1. Furthermore, a significant reduction in ovarian cancer risk was observed for the high tertile of serum adiponectin level versus the low (OR, 0.27; 95\%CI, 0.08-0.95) in Model 4 (Ptrend $=0.004$ ), as well as Models 1,2, and 3. Conversely, serum insulin level showed significantly elevated risk for ovarian cancer in the high tertile versus the low (OR, 6.64; 95\%CI, 2.48-17.77) in Model 2 (P trend<0.001), as well as in Model 1. However, serum genistein or equol levels were not associated with the risk of ovarian cancer risk in any model of this study.

Table 3 showed the relationship of the histologic types of epithelial ovarian cancer cases with age, serum isoflavones, adiponectin, and insulin levels, compared to the controls. As a result, serum daidzein levels, in cases with clear cell carcinoma, were significantly lower than that in the controls $(\mathrm{p}<0.01$, after Bonferroni correction). Serum insulin levels in cases with clear cell carcinoma

Table 2. Adjusted Odds Ratio (OR) and $95 \%$ Confidence Interval (95\% CI) for the Epithelial Ovarian Cancer Cases Compared with the Controls

\begin{tabular}{|c|c|c|c|c|c|}
\hline & & $\begin{array}{c}\text { Low } \\
\text { Reference }\end{array}$ & $\begin{array}{c}\text { Middle } \\
\text { ORs }(95 \% \text { CI) }\end{array}$ & $\begin{array}{c}\text { High } \\
\text { ORs }(95 \% \mathrm{CI})\end{array}$ & $\mathrm{P}$ for trend \\
\hline \multirow[t]{3}{*}{ Genistein } & Cases / Controls & $22 / 25$ & $34 / 28$ & $15 / 27$ & \\
\hline & Model 1 & 1.00 & $1.68(0.77-3.71)$ & $0.74(0.31-1.78)$ & 0.142 \\
\hline & Model 3 & 1.00 & $1.44(0.63-3.35)$ & $0.61(0.25-1.53)$ & 0.164 \\
\hline \multirow[t]{3}{*}{ Daidzein } & Cases / Controls & $37 / 27$ & $27 / 27$ & $7 / 26$ & \\
\hline & Model 1 & 1.00 & $0.71(0.33-1.50)$ & $0.20(0.07-0.52)$ & 0.004 \\
\hline & Model 3 & 1.00 & $0.54(0.24-1.22)$ & $0.13(0.05-0.38)$ & $<0.001$ \\
\hline \multirow[t]{3}{*}{ Glycitein } & Cases / Controls & $44 / 40$ & $19 / 14$ & $8 / 26$ & \\
\hline & Model 1 & 1.00 & $1.13(0.49-2.62)$ & $0.27(0.11-0.67)$ & 0.012 \\
\hline & Model 3 & 1.00 & $0.98(0.41-2.36)$ & $0.20(0.08-0.55)$ & 0.005 \\
\hline \multirow[t]{5}{*}{ Equol } & Cases / Controls & $58 / 59$ & & $13 / 21$ & \\
\hline & Model 1 & 1.00 & & $0.61(0.29-1.30)$ & $\mathrm{p}=0.200$ \\
\hline & Model 2 & 1.00 & & $0.47(0.15-1.52)$ & $\mathrm{p}=0.206$ \\
\hline & Model 3 & 1.00 & & $0.58(0.25-1.32)$ & $\mathrm{p}=0.299$ \\
\hline & Model 4 & 1.00 & & $0.37(0.11-1.33)$ & $\mathrm{p}=0.128$ \\
\hline \multirow{5}{*}{ Adiponectin } & Cases / Controls & $27 / 29$ & $36 / 25$ & $8 / 26$ & \\
\hline & Model 1 & 1.00 & $1.68(0.77-3.68)$ & $0.28(0.09-0.82)$ & 0.003 \\
\hline & Model 2 & 1.00 & $1.83(0.81-4.12)$ & $0.33(0.11-1.02)$ & 0.007 \\
\hline & Model 3 & 1.00 & $1.77(0.77-4.07)$ & $0.23(0.07-0.72)$ & $<0.001$ \\
\hline & Model 4 & 1.00 & $1.99(0.83-478)$ & $0.27(0.08-0.95)$ & 0.004 \\
\hline \multirow[t]{3}{*}{ Insulin } & Cases / Controls & $11 / 28$ & $13 / 26$ & $47 / 26$ & \\
\hline & Model 1 & 1.00 & $1.24(0.46-3.38)$ & $4.73(1.92-11.69)$ & $<0.001$ \\
\hline & Model 2 & 1.00 & $1.26(0.44-3.57)$ & $6.64(2.48-17.77)$ & $<0.001$ \\
\hline
\end{tabular}

Genistein: low $(<24.1 \mathrm{ng} / \mathrm{mL})$, middle $(24.1-106.4 \mathrm{ng} / \mathrm{mL})$, high $(\geq 106.5 \mathrm{ng} / \mathrm{mL})$; Daidzein: low $(<10.9 \mathrm{ng} / \mathrm{mL})$, middle $(10.9-43.8 \mathrm{ng} / \mathrm{mL})$, high $(\geq 43.9 \mathrm{ng} / \mathrm{mL})$; Glycitein: low $(<0.5 \mathrm{ng} / \mathrm{mL})$, middle $(0.5-2.2 \mathrm{ng} / \mathrm{mL})$, high $(\geq 2.3 \mathrm{ng} / \mathrm{mL})$; Equol; low $(<0.6 \mathrm{ng} / \mathrm{mL})$, high $(\geq 0.6 \mathrm{ng} / \mathrm{mL})$; Adiponectin: low $(<4.7 \mu \mathrm{g} / \mathrm{mL})$, middle $(4.7-9.6 \mu \mathrm{g} / \mathrm{mL})$, high $(\geq 9.7 \mu \mathrm{g} / \mathrm{mL})$; Iinsulin: low $(<4.1 \mu \mathrm{UI} / \mathrm{mL})$, middle $(4.1-6.9 \mu \mathrm{UI} / \mathrm{mL})$, high $(\geq 7 \mu \mathrm{UI} / \mathrm{mL}) ; \mathrm{Model} 1$ : adjusted for age, BMI, oral contraceptive use, use of fertility drugs, and parity; Model 2: adjusted for variables in Model 1 plus daidzein; Model 3 : adjusted for variables in Model 1 plus insulin; Model 4: adjusted for variables in Model 1 plus daidzein and insulin

Table 3. Comparison of Age, Serum Isoflavones, Adiponectin and Insulin Levels among the Cases with Histologic Types of Ovarian Cancer and the Controls

\begin{tabular}{lcccccc}
\hline & $\begin{array}{c}\text { Serous } \\
\text { carcinoma }\end{array}$ & $\begin{array}{c}\text { Endometrioid } \\
\text { carcinma }\end{array}$ & $\begin{array}{c}\text { Clear cell } \\
\text { carcinoma }\end{array}$ & $\begin{array}{c}\text { Mucinous } \\
\text { carcinoma }\end{array}$ & Unknown type & Control \\
\hline Number & 30 & 18 & 14 & 4 & 5 & 80 \\
Age (years) & $58.0(11.9)$ & $54.4(12.1)$ & $55.9(10.4)$ & $65.8(6.7)$ & $61.8(15.0)$ & $56.3(14.5)$ \\
Genistein $(\mathrm{ng} / \mathrm{mL})$ & $44.7[23.0,75.5]$ & $54.6[8.3,192]$ & $34.4[11.3,52]$ & $52[22.7,102]$ & $113[40.8,226.7]$ & $49.9[20.2,143.1]$ \\
Daidzein $(\mathrm{ng} / \mathrm{mL})$ & $12.3[5.5,23.1]$ & $11.7[2.6,25.7]$ & $5.5[2.2,9.8] \mathrm{gP} 1$ & $9.3[4.6,17.6]$ & $25.5[8.6,53.1]$ & $22.2[7.1,67.7]$ \\
Glycitein $(\mathrm{ng} / \mathrm{mL})$ & $1.3(1.7)$ & $0.9(0.9)$ & $0.7(0.4) *$ & $0.1(0.3)$ & $1.8(1.5)$ & $2.8(4.7)$ \\
Equol $(\mathrm{ng} / \mathrm{mL})$ & $0.7(0.9)$ & $5.1(9.2)$ & $1.4(1.9)$ & $2.3(3.7)$ & $5.4(8.4)$ & $4.0(10.0)$ \\
Adiponectin $(\mu \mathrm{g} / \mathrm{mL})$ & $6.2(3.1)$ & $6.0(3.3)$ & $6.0(3.4)$ & $4.4(0.9)$ & $6.4(2.6)$ & $7.9(5.6)$ \\
Insulin $(\mu$ IU.mL) & $9.4(7.3)$ & $11.0(5.1)$ & $15.4(12.0) \Phi \mathrm{P} 2$ & $13.2(9.1) \mathrm{IP} 3$ & $18.2(17.9)$ & $7.1(6.0)$ \\
\hline
\end{tabular}

Values are expressed as means (SD) or medians [interquartile range]. $I \mathrm{p}<0.05$ after Bonferroni correction; P1 and P2 presented comparisons beween the cases with clear cell carcinoma and the controls; $\mathrm{P} 3$ presented comparison between the cases with mucinous carcinoma and the controls 
as well as mucinous carcinoma were significantly higher than those in the controls (both, $\mathrm{p}<0.01$ after Bonferroni correction). Other comparisons did not reveal differences among the cases with different histological types, or differences between the cases and the controls.

\section{Discussion}

Consistent with previous studies showing the preventive effect of isoflavones against ovarian cancer (Lee et al., 2014; Rossi et al., 2008; Chang et al., 2007; Zhang et al., 2004), our study has indicated that low serum daidzein and glycitein levels were associated with increased risk for ovarian cancer. Especially, we observed significantly decreased daidzein levels in ovarian cancer cases with clear cell carcinoma as the specific histologic type. As a biological explanation for the protective effect of isoflavones against ovarian cancer, isoflavones have been shown to induce apoptosis and inhibit the growth and proliferation of ovarian cancer cells (Gossner, 2007). Another plausible mechanism is through antiestrogenic effects on ovarian cancer cell lines, since it is well known that ovarian cancer is an estrogen-dependent cancer.

Our study has also shown that low serum adiponectin levels are associated with an elevated risk of ovarian cancer. Although epidemiological studies on the association between serum adiponectin levels and ovarian cancer risk have been scarcely reported, as far as our knowledge, adipokines signaling pathways were suggested to be involved in ovarian follicle development and ovarian cancer (Dupont, et al., 2012). Furthermore, low adiponectin antagonizes many effects of TNF- $\alpha$, and have been recognized as a key regulator of insulin sensitivity and tissue inflammation (Lihn et al., 2005, Fantuzzi, 2005). TNF- $\alpha$, a major inflammatory cytokine, is abundant in the ovarian cancer microenvironment, and chronic inflammation may be implicated in the pathophysiology of ovarian cancer.

In this study, the high tertile of insulin levels had an approximately fivefold risk of ovarian cancer through mechanisms other than obesity, because a significant relationship was still observed even after adjustment of BMI. IGF-I has been implicated in the regulation of ovarian epithelial cell proliferation (Lukanova, et al., 2002), and this may provide an etiological explanation for increased risk of insulin for ovarian cancer risk. As another possible mechanism of IGF-I involvement in ovarian carcinogenesis, an experimental study has shown that the malignant transformation of ovarian cells can be induced by overexpression of IGF-1 receptors (Coppola et al., 1999).

We conducted histologic comparisons of ovarian carcinoma in terms of serum levels of measured substances, because of different risk factors (Risch et al., 1996), and because different morphologic properties (Soslow, 2008) have been shown among various types of histopathology in ovarian cancer. Significantly lower serum daidzein levels and significantly higher serum insulin levels were observed in the cases with clear cell carcinoma. Furthermore, significantly higher serum insulin levels were noted in cases with mucinous cell carcinoma.
However, the sample size of each histopathology was not enough to conclude these characteristics. Further study is necessary to confirm them.

As a major limitation of this study, the study design was a hospital-based case-control study, where controls were recruited only from inpatients who might have characteristics different from the general population. This may have resulted in a biased estimate of the association between exposure and diseases. Secondly, because the sample size was limited, type II errors might exist in the study. In addition, because only Japanese women were studied, our results may not be applicable to other racial/ ethnic groups.

In conclusion, decreased serum isoflavones levels, such as those for daidzein and glycitein, decreased serum adiponectin levels, and increased serum insulin levels are shown to be associated with an elevated risk of ovarian cancer.

\section{Acknowledgements}

This research was supported by the Grant-in -Aid for Scientific Research (B) (Projects Number 22390135) from the Ministry of Education, Culture, Sport, Science and Technology in Japan.

\section{References}

Ayyildiz T, Dolar E, Ugras N, et al, (2014). Association of adiponectin receptor (Adipo-R1/R2) expression and colorectal cancer. Asian Pacific J Cancer Prev, 15, 9385-90.

Brokaw J, Katsaros D, Wiley A, et al (2007). IGF-1 in epithelial ovarian cancer and its role in disease progression. Growth Factors, 25, 346-54.

Chang ET, Lee VS, Canchola AJ, et al (2007). Diet and risk of ovarian cancer in the california teachers study cohort. Am J Epidemiol, 165, 802-13.

Collaborative Group on Epidemiological Studies of Ovarian cancer, Bera V, Doll R, et al (2008). Ovarian cancer and oral contraceptives; collaborative reanalysis of data from 45epidemiological studies including 23,257 women with ovarian cancer and 87,303 controls. Lancet, 371, 303-14.

Coppola D, Saunders B, Fu L, et al (2007). The insulin -like growth factor 1 receptor transformation and tumorigenicity of ovarian mesothelial cells and down-regulates their Fas -receptor expression. Cancer Res, 59, 3264-70.

Dupont J, Reverchon M, Cloix L, et al (2012). Involvement of adipokines, AMPK, PI3K and the PPAR signaling pathways in ovarian follicle development and cancer. Int J Dev Biol, 56, 959-67.

Fantuzzi G (2005). Adipose tissue, adipokines, and inflammations. J Allergy Clin Immunol, 115, 911-9.

Giovannucci E (1995). Insulin and colon cancer. Cancer Causes Control, 6, 164-79.

Gossner G, Choi M, Tan L, et al (2007). Genistein-induced apoptosis and autophagocytosis in ovarian cancer cells. Gynecol Oncol, 105, 23-30.

Gulcelik MA, Colakoglu K, Dincer H, et al (2012). Association between adiponectin and two different cancers; breast and colon. Asian Pac J Cancer Prev, 13, 395-8.

Horn-Ross PL, John EM, Canchola AJ, et al (2003). Phytoestrogen intake and endometrial cancer risk. J Natl Cancer Inst, $\mathbf{9 5}$, 1158-64.

Kaaks R, Toniolo P, Akhmedkhanov A, et al (2000). Serum 
C-peptide, insulin -like growth factor (IGF)-1, IGF-binding proteins, and colorectal cancer risk in women. J Natl Cancer Inst, 92, 1592-600.

Lee AH, Su D, Pasalich M, et al (2014). Soy and isoflavone intake associated with reduced risk of ovarian cancer in southern Chinese women. Nutr Res, 34, 302-7.

Lee MM, Gomez SL, Chang JS, et al (2003). Soy and isoflavone consumption in relation to prostate cancer risk in China. Cancer Epidemiol Biomarkers Prev, 12, 665-8.

Lihn AS, Pedersen SB, Richelsen B (2005). Adiponectin; action, regulation and association to insulin sensitivity. Obes Rev, 6, 13-21.

Luhn P, Fallal CM, Weiss JM, et al (2013). Circulating adipokine levels and endometrial cancer risk in the prostate, lung, colorectal, and ovarian cancer screening trial. Cancer Epidemiol Biomarkers Prev, 22, 1304-12.

Lukanova A, Lundin, Toniolo P, et al (2002). Circulating levels of insulin-like growth -1 and risk of ovarian cancer. Int $J$ Cancer, 101, 549-54.

Parkin DM, Bray F, Ferlay J, et al (2005). Global cancer statistics, 2002. CA Cancer J Clin, 55, 74-108.

Piver MS, Goldberg JM, Tsukada Y, et al (1996). Characteristics of familial ovarian cancer; a report of the first 1,000 Families in the Gilda Rander Familial ovarian cancer registry. Eur J Gynaecol Oncol, 17, 169-76.

Qu X-L, Fang Y, Zhang M, Zhang Y-Z (2014). Phytoestrogen intake and risk of ovarian cancer; a meta-analysis of 10 observational studies. Asian Pac J Cancer Prev, 15, 9085-91.

Risch A, Marrett LD, Jain M, et al (1996).Differences in risk factors for epithelial ovarian cancer by histologic type. Results of a case-control study. Am J Epidemiol, 144, 363-72.

Rizzuto I, Behrens RF, Smith LA (2013). Risk of ovarian cancer in women treated ovarian stimulating drugs for infertility. Cochrane Database Syst Rev, 8.

Roberts DL, Dive C, Renehan AG (2010). Biological mechanisms liking obesity and cancer risk; new perspectives. Annu Rev Med, 61, 301-16.

Rossi M, Negri E, Lagiou P, et al (2008). Flavonoids and ovarian cancer risk; A case-control study in Italy. Int J Cancer, 123, 895-8.

Rüfer CE, Glatt H, Kulling SK (2006). Structural elucidation of hydroxylated metabolites of the isoflavone equol by gas chromatogtaphy-mass spectrometry and high-performance liquid chromatography -mass spectrometry. Drug Metab Dispos, 34, 51-60.

Schoen RE, Tangen CM, Kuller LH, et al (1999). Increased blood glucose and insulin, body size, and incident colorectal cancer. J Natl Cancer Inst, 91, 1147-54.

Soslow RA (2008). Histologic subtypes of ovarian carcinoma; an overview. Int J Gynecol Patho, 127, 161-74.

Troisi R, Potischman N, Hoover RN, et al (1997). Insulin and endometrial cancer. Am J Epidemiol, 146, 476-82.

Valladares M, Corsini G, Romero C (2014). Association between obesity and ovarian cancer. Rev Med Chil, 142, 593-8.

Wang XL, Hur HG, Lee JH, et al (2005). Enantioselective synthesis of $\mathrm{S}$ equol from dihydro- daidzein by a newly isolated anaerobic human intestinal bacterium. Appl Environ Microbiol, 71, 214-9.

Yamamoto S, Sobue T, Kobayashi M, et al (2003). Soy, isoflavones, and breast cancer risk in Japan. J Natl Cancer Inst, 95, 906-13.

Zhang M, Xie X, Lee AH, et al (2004). Soy and isoflavone intake are associated with reduced risk of ovarian cancer in Southeast China. Nutr Cancer, 49, 125-30. 